УДК 8127

ББК 81

DOI: https://doi.org/10.17308/lic.2020.3/2943

\title{
О МИФАХ И МИФОЛОГЕМАХ ЛИНГВОКУЛЬТУРЫ: ДУХОВ ДЕНЬ - ИМЕНИНЫ ЗЕМЛИ
}

\author{
Е. А. Мошина \\ Военный институт (инженерно-технический) \\ Военной академии материально-технического обеспечения имени генерала армии А. В. Хрулёва
}

\section{MYTHS AND MYTHOLOGEMES OF THE LINGUISTIC CULTURE: SPIRITS DAY - BIRTHDAY OF THE EARTH}

\author{
E. A. Moshina \\ Military Institute (Engineering and Technical) \\ of the Military Academy of Material and Technical Support Army General A. V. Khrulev
}

\begin{abstract}
Аннотация: в статье рассматривается мифологема «земля» в русской лингвокультуре. Цель статьи описать особый праздник земли, связанный с культом предков. Этот праздник известен как Духов день. У него есть другое название - именинь земли. В этот день чествуют землю-мать. Задачи статьи: 1) установить характеристики праздника; 2) описать сопряженные с этим праздником символь русской лингвокультуры; 3) восстановить мотив забытого мифа о земле-матери; 4) выявить признаки мифологемь «земля», сохранившиеся в языковом сознании русских. Актуальность проводимого исследования заключается в верификации данных русской культуры в собранном языковом материале, определении преемственности символики земли в лингвокультуре при смене религий. Научная новизна работы состоит в обращении к теме мифологемы «земля» в лингвокультурологическом аспекте. В лингвистике не существует работ, посвященных исследованиюмифологемы «земля», представленных в когнитивном илингвокультурологическом ракурсах. Материал исследования собран из словарей, художественной литературы и Национального корпуса русского языка (www.ruscorpora.ru). Методами исследования являются описательный, интерпретативный, концептуальный. Как показало проведенное исследование, в русской лингвокультуре прочно закрепился символ Земли-матери. Этот символ не смогла искоренить пришедшая на смену язычеству религия, так как в русском языковом сознании мать является высочайтей святыней, которую нельзя свергнуть. Сама Россия ассоииируется с матерью, как и земля, на которой она стоит. Мифологема «земля» указывает на существование культа предков. Как показывает анализ собранного языкового материала, этот культ связан с мифом о иерогамии - священном браке между небом-солнцем и землей. По одной из версий супругом земли считался Перун. Все сущее на земле - это дети этой божественной пары. День этого священного брака - Духов день - отмечался на следующий день после Троищь. Троица до принятия христианства у русского народа была иной. В нее входили три важных ипостаси мира солние, небо и земля. Духов день - это праздник возрождения природы. Его характеристиками было тепло (солние, жара), дождь (проявление оплодотворяющей силь неба-Перуна) и сама земля, расцветающая и готовая к новому ичиклу рождения.
\end{abstract}

Ключевые слова: символ, миф, мифологема, языковое сознание, русская культура, лингвокультура.

Abstract: the article considers the mythologeme "earth" in the Russian linguistic culture. The purpose of the article is to describe a special holiday of the earth associated with the cult of ancestors. This holiday is known as the Spirits Day. It has another name - the birthday of the earth. On this day, the Mother Earth is honored. The objectives of the article are: 1) define the characteristics of a holiday; 2) describe symbols of Russian linguistic culture associated with this holiday; 3) restore the motive of the forgotten myth of the mother-earth; 4) identify the signs of the mythologeme "earth" preserved in the language consciousness of the Russians. The relevance of

(C) Мошина Е. А., 2020

Контент доступен под лицензией Creative Commons Attribution 4.0 License.

The content is available under Creative Commons Attribution 4.0 License. 
the study is to verify the data of Russian culture in the collected language material, to determine the continuity of the earth symbols in linguistic culture during the change of religions. The scientific novelty of the work is that we discuss the mythologeme "earth" as the aspect of linguistic culture. There are no works in linguistics devoted to the study of the mythologeme "earth", considering it from the cognitive and linguoculturological positions. The material of the study is collected from dictionaries, fiction and the Russian National Corpus (www.ruscorpora.ru). The methods used in the study are descriptive, interpretive, conceptual. According to the study, the symbol of the Mother Earth is firmly fixed in Russian linguistic culture. Christianity that replaced paganism, failed to eradicate this symbol because in Russian language consciousness the mother is the highest shrine that cannot be overthrown. Russia itself is associated with mother, as well as the land it stands on. Mythologeme "earth" indicates the existence of a cult of ancestors. As the analysis of the language data shows, this cult is related to the myth of hierogamy ('holy marriage') - the sacred marriage between the sky-sun and the earth. According to one version, Perun was considered to be the spouse of the Earth. Everything on earth is the offspring of this divine couple. The day of this sacred marriage - Spirits Day - was celebrated the day after Trinity. Before the adoption of Christianity, the trinity had a different conception for Slavic people. It included three important hypostases of the worldthe sun, the sky and the earth. Spirits Day is a celebration of the revival of nature. Its characteristics were warmth (sun, heat), rain (manifestation of the fertilizing power of heaven-Perun) and the earth itself, blossoming and ready for a new birth cycle.

Key words: symbol, myth, mythologeme, language consciousness, Russian culture, linguistic culture.

\section{Введение}

Статья посвящена изучению мифа о забытом празднике земли в русской лингвокультуре. Миф о чествовании земли, весеннем празднике, который бытовал у наших предков, современникам практически неизвестен.

В русской лингвокультуре прочно утвердился праздник Духов день, который справляется обычно в мае, но иногда этот день выпадает на другой месяц, так как дата его празднования связана с Троицей тоже нефиксированным жестко днем. «Духов день (День Святого Духа) - христианский и народный праздник, отмечаемый по православному календарю на следующий день после Дня Святой Троицы. Для восточнославянской народной традиции характерны поверья о том, что земля на Духов день - именинница, потому что “в этот день она сотворена”. В народной традиции с Духовым днем часто связаны грозы (ср.: Люблю грозу в начале мая. Ф. И. Тютчев); по другим поверьям, погода в Духов день определяет и погоду на ближайшие 6 недель - на все оставшееся лето. Считалось, что в Духов день земля беременна урожаем, и поэтому ее нельзя трогать: пахать, боронить, копать, засевать, вбивать колья и палки. По поверьям, в самый Духов день, перед восходом солнца, Мать Сыра-Земля открывает свои тайны: многие, помолясь Святому Духу, ходили “слушать клады”, припадая к земле ухом (но утверждалось при этом, что открывались земные и подземные тайны только истинным праведникам, благочестивым людям)» [19, c. 127].

\section{Материал и методы исследования}

Материалом исследования послужили данные словарей, примеры из художественной литературы, представленные в Национальном корпусе русского языка (www.ruscorpora.ru). Методами исследования являются описательный, интерпретативный, концептуальный.

Определимся с основными терминами. «Мифом будем называть сказание, в котором отображено первобытное мировоззрение, которое <..> рассматривается как определенная система символов и знаков, которые нуждаются в истолковании, а для его носителей были действительностью, мифической реальностью» [2, с. 141].

Теория мифа активно разрабатывалась такими зарубежными исследователями, как Р. Барт, К. Леви-Стросс, Е. Б. Тайлор, В. Р., Дж. Фрезер, М. Элиаде, К.-Г. Юнг и др. [3-8]. В России теория мифа представлена трудами отечественных ученых В. П. Аникина, А. Н. Афанасьева, Ф. И. Буслаева, А. Ф. Лосева, Ю. М. Лотмана, Е. М. Мелетинского, А. А. Потебни и др. [9-16]. В XX в. к мифу обратились литературоведы, «поскольку вся художественная литература наполнена мифами, мифическими сюжетами и мифологемами. Если раньше история развития цивилизации двигалась в направлении “демифологизации”, то в XX в. мы наблюдаем “ремифологизацию”» [17, c. 4]. Не все древние мифы восстановлены. Эта тема - кладезь для исследователей разных научных направлений, в том числе лингвокультурологов и когнитологов $[1 ; 18 ; 19]$.

Воссозданию архаичных мифов поможет подробное изучение мифологем. Термин мифологема многогранен. Мифологема представляет собой след обычно утраченного мифа. Ее можно отыскать в фольклорном тексте (который зачастую сохраняется в отрывочном виде): мифологема в таком тексте воспринимается как аллегория, выдумка, сказка.

Мифологема в языковом сознании существует в виде образа либо традиционной сюжетной схемы. Отголоски существования мифологемы можно оты- 
скать в календарных датах и забытых праздниках, связанных с ними. Мифологема встроена в систему традиционных культурологических парадигм. Язык аккумулирует когнитивные признаки мифологемы в виде стертых метафор и устойчивых выражений.

Одно из перспективных направлений когнитивной лингвистики и лингвокультурологии - исследование забытых мифов и обусловленных ими мифологем. К таким мифам относится праздник Духов день и мотив именин земли, связанный с этим днем.

Мифологема земля привлекала исследователей разных культур. В лингвистике есть работы, в которых исследовались балто-славянские мифы о Земле-Матери $[20 ; 21]$. Однако в этих статьях ничего не говорится о празднике земли, который называется по-разному. В этом и заключается научная новизна проводимого исследования.

\section{Результаты и их обсуждение}

До прихода христианства у славян была иная Троица. Во-первых, было празднование трех важных дней: Семика, самой Троицы и Духова дня (B paзных губерниях Семик справляли то в четверг накануне Троицы, то в саму Троицу, то в следуюший за нею Духов день. Этот праздник знаменовал иную, земледельческую, Троицу: гармоничное единение жювотворного света Солнца, благодатных вод, проливающихся с небес, и плодотворной силы Земли, пробужденной весенним теплом. Семик непременно справляли среди природы; украшали («завивали») березку, водили под ней хороводы с обрядовыми песнями, приносили ритуальное угощение, часть которого оставляли под деревом или разбрасывали по распаханному полю, гадали на зеленых венках о своей судьбе, а главное - просили хорошего урожая. И. Грачёва. Храм над Окой). Здесь мы видим не традиционную дихотомию сил, а трихотомию, более свойственную народному сознанию, объединяющую свет, воду и землю - три важных стихии, дающих жизнь и поддерживающих ее функции.

Ключевой эпитет земли, связанный с Духовым днем - земля-именинница. Рассмотрим этот эпитет подробнее.

Как показывает собранный материал, этот эпитет встречается в современных контекстах XXI в. Вот пример 2013 г. (А вокруг праздник, ну просто земля-именинница! На площзади у остановки мангаль с шашльками, с грузовика пивом торгуют, лотки со «сникерсами» стоят для детишек, музыка орет из репродукторов. Народу видимо-невидимо! А. Моторов. Преступление доктора Паровозова). Еще один пример 1954 г. (И низкой своей октавой продолжал: «В Духов день земля именинница»... Дон Аминадо. Поезд на третьем пути). Большая часть иллюстратив- ных примеров относится к русской классике - литературе XVIII-XIX вв.

Именины земли - это праздник для всех. Весной, чаще в мае, земля нарядна и вся в цвету (Земля смотрела именинницей Ивсе ждала неделю эту, Когда к ней избавитель кинется Под сумерки или к рассвеmy. Б. Л. Пастернак. Одесса). В Духов день нельзя было пахать землю (23 мая. Земля именинница. Заповедь для всех: «В этот день пахать грех». Земля omдыxaеm. П. Рожнова. Обереги Полины // Наука и религия. 1992). С принятием христианства акценты с земли переносятся на бога: Духов день приобретает иной смысл (Завтра вся земля именинница. Потому - Господь ее посетит. И. С. Шмелев. Лето Господне).

В первой книге «В лесах», написанной в18711874 гг, П. И. Мельников-Печерский именины земли описывает в ряду других забытых славянских праздников (Местами зовут его "Яр-Хмель» - отсюда «хмелевые ночи», то есть весенние хороводы и другие игры молодежи, продолжающиеся до утренней зари. Радуница, Красна Горка, Русальная неделя, Бисериха, Земля-именинница (10мая), Семик, Зеленые святки, Девята пятницуа, Ярило Кострома, Клечаль, Кукушки, Купало, хороводь:: радуницкие, русальные, никольщуина, зилотовы, семицкие, троицкие, всесвятские, пятницкие, ивановские или купальские - все это ряд праздников одному и тому же Яриле, или Купале. На Радунииу празднуется его приход, на Купалу - похороны, причем в некоторых местах хоронят соломенную куклу, называемую Ярилой, Костромой, Кострубом и пр. От Фоминой недели до Ивана дня (Иван Купало 24 июня) продолжаются «хмелевые ночи», $и$ это самое веселое время деревенской молодежи. П. И. Мельников-Печерский. В лесах). Он описывает обрядовые действия, сопровождающие этот праздник: веселые песни, хороводы (Завив венки, иелуются через них и «кумятся» при звонких весельх песнях: Зилотовы хороводы справляются в день, когда «Земля именинница», 10 мая. П. И. Мельников-Печерский. В лесах).

В русском языке есть два значения у слова именuныl: «1) День памяти какого-л. святого, являющийся праздником для того лица, которое при крещении названо по имени этого святого (у православных и католиков, соблюдающих церковно-бытовые обряды). 2) Празднование, устраиваемое в связи с таким днем» [22]. В христианстве земля не относится к пантеону святых, следовательно, в примерах мы видим употребление слова во втором значении: «Празднование, устраиваемое в связи с таким днем». Название праздника - Духов день - прямо указывает тех, в честь кого устраивался праздник - духов. Духами в русском языке считают дохристианских богов, которых при смене религии стали причислять к нечистой силе. 
Признаки силы и теоморфности встречаются в описаниях земли в языковом материале ( $B$ ее поэзии ошущзается нечто исходящее из самых пучин, «хтоническое» - то есть олицетворяющчее древнюю природную мощьь Земли. Из всех богов Шкапской была ближе всех Гея, Мать-Сыра-Земля. С. Макин. Mater Dolorosa - Мать Скорбящая). Все хтонические

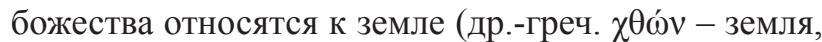
почва).

Именинами часто называют день рождения. У земли отмечен признак 'дня рождения' (Tbl-как день, когда земля рожналась, вся в заре, в сверкании светил. О. Ф. Берггольц. Встреча с победой). В день рождения женщинам в русской культуре принято дарить цветы. Но никто сейчас не задумывается, что эта традиция восходит к культу земли - матери. Ей было принято дарить цветы в Духов день, когда земля празднует именины (Таким образом, нынешние весенние праздники св. Трочцы и Духов день будут без традиционных березок и цветов, что огорчит пригородных крестьян, зарабатывавиих кое-что на этих праздниках, но вместе с тем сохранит жизнь нескольким тысячам молодых деревьев, гибнущих, что называется, во иявете лет, благодаря установившемуся обычаю украшать дома молодой зеленью. Троица без березок // Петербургская газета. 1909. 26 мая).

Имя богини земли в русской лингвокультуре тоже сохранилось. Это Макошь (Праобразом христианской Параскевы-Пятнищы была древнеславянская богиня Мокошь (Макошь, Мокша). По верованиям она и есть мать Сыра-Земля. Мокошь в виде женщины с большой головой и вытянутыми ввысь длинныли руками олицетворяла взаимодействие сил земли и неба. А. Клейн, О. Шотландия. Ноябрь). Первый слог имени богини земли явно связан с детским словом ма, обозначающим «мама, мать» (Имени нельзя ей дать Сильнее и нежней, чем слово: мать - земля. В. А. Меркурьева. Я вам даю в утеху и в угоду...). Светлана Анатольевна Еремеева в своих лекциях говорила: «Сначала, еще в эпоху матриархата, возникает культ великой богини, постепенно принимающий черты культа земли, земного плодородия. Богиня земли постепенно становится как бы матерью всего сущего: полей, растений, деревьев, зверей, - Великой Матерью» [21].

При смене религии происходит переоценка прежних верований. «Чистый дух - Бог, нечистый - демон (нечистый дуx - устар.). Демоны - это явление, связанное с дохристианскими представлениями народа о природе, его окружающей. Демоническое, вероятно, заключалось в их облике - в совмещении зооморфных и антропоморфных признаков, но не обязательно» $[23$, с. 200]. Боги, которым поклонялись ранее, переходят в иной ранг: «после принятия христианства языческие божества были провозглашены демонами» $[24$, c. 51]. С приходом христианства земля - величайшая ценность в русской лингвокультуре - становится глиной, простым веществом (Kmo Mbl / Возомнившие себя повелителями / И творияами / Кто Мы / С этими трущобами / И дворияами / Кто Мьл / Частиия Святаго Духа / А Земля / Что она в сравнении с состоянием / Пятого вещества / Клок пуха / Как это понять / Постичь / Не понять / Не достичь. И. С. Холин. Кто Мы...). Земля обесценивается, десакрализуется (Коснется нас мудрой рукой Творец - И в жизнь облекается серый прах; И ты, и земля, илист, и скворец - Мы все только глина в Его руках. Л. А. Алексеева. Я липовый лист в лесу сорвала...). Десакрализация приводит к тому, что прежние важные праздники уходят из быта народа. Однако отголоски ритуалов сохраняются в культуре. Например, ритуал дарения цветов в день рождения женщины.

Земля в славянской традиции почиталась матерью - отсюда ее эпитеты: Мать-сыра земля, земля-матушка. Основная функция матери - рождение детей. Метафоры рождения чрезвычайно частотны в описаниях земли (Так до самой Тамани, до самой Тамани, А земля, как назло, неустанно родит. С. И. Липкин. На свежем корчевье). Природа, рождение, плодородие - однокоренные слова, связанные с символикой земли (Земля недаром столько раз рожсала, Морская соль недаром несладка. П. Г. Антокольский. Сожженная земля в колючках дрока...). Этот ряд однокоренных слов продолжают урожай и народ $(O$, земля, частица древней нивы, Божий урожай, в веках созрельй! О, земля, я сльишу, - ты устала. Скоро час последней судной жатвы. Е. Ю. Кузьмина-Караваева. Черные фигуры двух монахинь...), родство и родной (Святое, грозное пламя Отмщченья, бушуй в груди! Родная земля - за нами. Земля врага - впереди. А. Т. Твардовский. Граница), Родина (Ведь земля -для кочевья, Всюду родина, было б немного травы. С. И. Липкин. На свежем корчевье). Родина - та земля, где появился на свет человек (И горьким плачем огласил Ту землю, где на свет родился. Ю. П. Кузнецов. Меня по миру вихрь носил...). Люди - это сыновья земли-матери (Газета проглочена залпом - $u$ запах, и шорох, и свет разъело, разъяло внезапным предгрозьем, и воздуха нет земле - с ее ростом растений, с полетом ее сыновей... Г. С. Семенов. Земля). Мать-земля оберегает своих детей, защищает их. Языковое сознание проносит архетипические признаки земли до нашего времени (И каждую ночь Большая земля, Как мать, окликала своих сынов: По радио Спасская башня Кремля Била 12 часов, И чудились в мире ночной синевы Родные рубины Moсквы. И. Л. Сельвинский. Баллада о танке «КВ»). Пафосность и высокий стиль сопровождают такие метафоры родства земли и людей, что указывает на 
существовавшую и сохранившуюся до сих пор ценность этих когнитивных признаков для русской лингвокультуры.

В русской лингвокультуре мать - самое ценное, что есть у человека (Мать-земля, что тебя дороже Для летавшего человека! П. Г. Антокольский. Возвращение). В качестве благодарности за свое рождение человек дарит любовь своей земле-матери (И вновь возникнет предо мной складная Скамеечка и яркий твой купальник, И вновь пойму, что вам я сопечальник: Тебе, любовь, тебе, земля родная. С. И. Липкин. 24 июня 1985 года).

Почитание матери прошло сквозь века. «Одна из самых больших святынь - мать сыра земля. К ней относятся как к женскому началу, рождающему и плодоносящему. У восточных славян этот древний индоевропейский культ сохранился в очень архаичных проявлениях - запрещение бить землю в неритуальных случаях, тревожить землю до определенного срока и плевать на нее» [21]. Земля для русского человека - святая сила (Одни, по его мнению, принимают мир таким, каков он есть, - позиция, близкая поэзии его отиза Н. С. Гумилева: Убивая и воскрешая, Набухать вселенской душой, В этом сила земли святая, Непонятная ей самой. А. Алексеев. Возвращение к фактам, или как восстановить единство истории).

Плодородие - важная характеристика земли - в русском языке актуализируется метафорами рождения. Плодами земли называется все, что на ней произрастает (В яблоке, даже незрелом, земля закруглелаи скажется грехопадением клону почвы овражистой, в ноги дождю и рождению смертного стона. В. Б. Кривулин. Гимнические строфы). И наоборот, беременность матери и рождение человека объективируются метафорами плода (Пьют поэты четверть века, Четки шевеля. Носит бремя человека Скорбная земля. Дайте крови, дайте хлеба, Вечной жизни плод. Ю. П. Одарченко. После выставки). Взаимозаменяемость таких метафор указывает на прочную связь признаков рождения, плодородия и земли.

Все этапы жизни - от зачатия до рождения - от малого до великого описываются метафорами семян (Смерть человека, смерть ичивилизаичи, смерть Земли, смерть вселенной; до этого - рождение человека, рождение циивилизации, рождение Земли, рождение вселенной; все проходит через семя, «почти ничто», и растет до тела, и во всем постоянно творит Бог. В. В. Бибихин. Из записей на тему самопознания). Антропоморфизм проявляется и в описаниях соматики человека и космоса: каждый из небесных объектов, в том числе и земля, называются небесным телом.

Символика плодородия в русской лингвокультуре обусловлена урожайностью земли, которое считается богатством (Потому что каждая страница - Мужества широкие поля, Песнями, легендами, пшеницей Русская богатая земля! М. А. Светлов. Двадцать восемь). Характеристики плодородия передаются по женской линии: от матери - к дочери - от дочери - к ее детям и т. д. (Мать сыра земля - наша истина, Через девицу сеет весточки, Через матуику сеет косточки, Через старицу сеет высевки. Ю. П. Кузнецов. Сито). Земля благословляла своих дочерей в свой праздник.

В праздник земли - в Духов день - было принято девушкам присматривать будущего мужа или ждать сватов (Где-где сердие обрящует упокоение, коли упокоения ему не будет и в Духов день? Густо гудит в ветер Абрам, ударяя по луже палкой: «Девицы-красавицы, светел теремок; гостя ждите, пейте пиво да медок. Путничек желанный недалек...» А. Белый. Серебряный голубь). В Санкт-Петербурге женихов присматривали в Летнем саду, прогуливаясь там в Духов день (Двадичать три года назад, в духов день, когда купиы выводят своих дочек на смотрины в Летний сад, так же вот, только куда гуще, понесло горелым над столичным иентром. Ю. М. Нагибин. День крутого человека). Духов день обусловлен еще и символикой продолжения рода.

Род - это семья, которая заботится о тех, кто в нее входит. От урожая зависит жизнь народа. Обязанность земли - матери - кормить своих детей (Обряд земли питать родные зерна, А осенью, под ветром, умирать - Я приняла любовно и покорно, Я научилась ничего не знать. Е. Ю. Кузьмина-Караваева. Обряд земли - питать родные зерна...). Земля учит своих детей труду, уважению, скромности, законам выживания (Я и сам одевался в убогую ветошь - Так меня мать-земля осторожно учила, - Чтобы мне горемыкой скитаться по свету, Чтобы смерть неприметного не различила. В. Блаженный. ...А степная травинка останется мною...). В семье человек получает первичные навыки жизни и узнает о традициях народа.

Землю почитали. Она была объектом поклонения. Культ земли связан с культом Великой Богини-матери [подробнее см. 1]. У многих народов существовал такой культ. Земле клали земные поклоны. «Мать-Земля была высшим нравственным авторитетом, выросшей из должности-необходимости, ставшей порядком-правилом, той последней и высшей инстанцией, перед которой несли ответственность, на суд которой выносили то, что не могло быть решено иначе» [25, c. 269, 272]. И если обычная мать только рождает дитя, то земля еще и забирает своих детей обратно (А коли мать, Молчи, шаля-валя, Должсна зараз детей примать, Как мать сыра земля. Ю. П. Кузнецов. Седьмой).

Весенний праздник Духов день ассоциируется с грозами (Но вот и пришел Духов день. Перед рассве- 
том бушевала мощңная июньская гроза. В. Михальский. Весна в Карфагене). Гроза - сочетание грома, дождя и молний - символы Перуна-громовержца. В балтийской традиции - у литовцев - мужем земли считался Перкунас [20, с. 498-499]. В славянской традиции у земли тоже есть супруг.

Как показывает языковой материал, божественную чету образовывали солнце и земля (Они признают два физических начала всех земных вещей: солнцее-отца и землю-мать. М. Шишкин. Письмовник), по другому варианту - небо и земля (И земля, наша добрая мать, она не сумела спасти нас от гнева неба-отца. Г. Садулаев. Одна ласточка еще не делает весны). В научной литературе брак неба и земли называется иерогамией (Царство истое, не оплошное, не иначе родиться может, как от иерогамии, свящценного брака меж землею и небесами. П. Крусанов. Укус ангела). Уранический вариант мужа земли связан с Геей - древнегреческой богиней земли. Древнегреческие мифы проникли в разные культуры. Этот вариант продолжается в персонифицированном мифе о Зевсе - внуке Урана - и Геры - богини земли (Прочнее всего держалось представление о Зевсе и Гере как об образијовой супружеской чете; их «свящзенный брак» (hieros gamos) был первообразом человеческого. Ф. Ф. Зелинский. История античной культуры). В русской лингвокультуре небо чаще встречается в описаниях божественного супруга земли (Светлеет жилье оседлое Кочевника-короля. Tbl-небо мое пресветлое, Возлюбленная земля. С. И. Липкин. Земля). С принятием христианства солнце и небо заменил не конкретизированный бог (Нет, говорю, у меня ни отцуа, ни матери, окроме бога и земли. Бог - отец, земля -мать. Л. Н. Толстой. Воскресение). Бог стал первичен по отношению к земле-матери, так как прообразом христианской Богородицы была именно Макошь, которая и представляла землю-мать.

Небо - это место обитания Перуна-громовержца. Вероятнее всего, супругом земли был именно он. В народных поверьях существует знание о влажной земле, которая родит, сухая земля неплодородна. Приметой Духова дня был дождь. В языковом материале дождь описывается метафорами сеяния - засевания земли (День Духов - на сердие спокойно; а там - сейся, дождь, окрестность - росой обливайся, $и$ вы, туманы, клубитесь - клокочите дождями, вы! А. Белый. Серебряный голубь).

Гром, вызывающий сотрясения земли, был символом Перуна (И хоть волною грозной ж⿻ара Я был далеко отстранен, Земля отчетливо дрожсала Под той кувалдой в тыщщи тонн. А. Т. Твардовский. Две кузницы). Сотрясение земли, содрогание от грома считается проявлением священного брака (Tonom тысяченогий Катится по дороге. Точно земля задро- жсала, Громом потрясена. И. В. Елагин. Человек на дороге...), а проливание дождя на землю определяет ее плодоносность. Гроза - проявление бога-громовержца Перуна в отношении земли, ее оплодотворение (А кругом / без конца и без края, В полнокровной грозе / половодьем бурля, Вся набухшая, / теплая / и сырая, Мне доверенная / Земля. А. П. Межиров. Я старожил своего батальона...). В Духов день - на именины земли - обязательно шел дождь. Дождь - это проявление божьей благодати - дара от бога Перуна живой земле-матери (Bom Господь завтра и посетит ее, благословит, А на Духов День, может, и дожжюк пошлет... божью благодать. Я смотрю на серую землю, и она кажется мне другой, будто она живая, - молчит только. И. С. Шмелев. Лето Господне).

В основе стертых метафор грозы и угрозы находятся признаки громовержца, мечущего грозу на землю (Так что ж они шуршат, шумят, скользят, пытаясь лечь не так, как вышло сразу, сейчас земля и свет небес грозят одной бедой - одною стужей глазу. И. А. Бродский. Пришла зима, и все, кто мог лететь...). Земля и Перун действуют совместно, объединяя свои силы, что описывается боевыми метафорами (Почему на тебя так сурово земля ополчилась и небо, И молвить боишься ты лишнее слово, Лиииться бродяжьего хлеба. В. Блаженный. Отец, я тебя узнаю по походке...).

Смена религии привела к однозначному результату: землю перестали почитать (Кому теперь воздать, кому молиться в мире, Чем стала для отияов моих земля, Когда и сам Господь в обличье конвоира Ярился, сапожищами пыля... В. Блаженный. Когда евреи шли толпою обреченной...). Из родительницы земля превращается в нечто вторичное, сотворенное богом (Грядет Суббота - / День Шестый, день завершенья / всех стихий. Все создано: / Земля и Свет. Но Человека только нет. С. И. Кирсанов. День шестой). Земля становится местом упокоения - могилой, после смерти человека душа человека, согласно новой вере, предстает пред очами бога (Могила кольбелью будет им, Земля - началом жсизни чудотворной. Е. Ю. Кузьмина-Караваева. Похвала труду). В Древней Греции формируется учение о первостихиях, где земля - одно из первоначал всего сущего (Земля, воздух, пламя и водь владеют и днесь мирозданьем. А. С. Присманова. Природа).

Праздник земли связан с предками, ушедшими на тот свет. «В славянских традициях существовал культ предков. Скорее всего, $\partial y x$ - это умерший предок, что подтверждается фактом существования особого праздника, посвященного предкам - Духов день (в англ.: All Soul's Day), отсюда - представления о привидениях или призраках - духах (вызылвать духов), а также христианские представления об их отношении к тьме» [23, с. 200]. Другими словами, земля - это 
богиня. В русском языковом сознании родственные связи людей с землей закрепились в ее постоянном эпитете - матушка/мать. Славянский культ земли-матери - это отголоски культа Великой Богини-матери, который исповедовали практически все народы. У русского народа с землей связано много примет и поверий, что указывает на ее значимость и особый статус.

«Изучение мифологемы Земля-мать показало, что в русской лингвокультуре существует устойчивый образ древней богини - Матери-сырой-земли. Этот образ воплощает черты забытого культа вследствие смены религии, произошедшей у русского народа. Данная мифологема актуализируется в языковом материале посредством признаков 'мать', 'родительница', ‘кормилица', ‘повелительница', 'дарующая блага / благодетельница', ‘хозяйка', ‘теща', ‘жена бога'» [1, с. 257].

В Духов день было принято ходить на кладбище поминать предков (Ходили по случаю Троицы на кладбище. Сегодня Духов день. Что за день - не знаю. Говорят, праздник важнее, чем Троииа. Д. Каралис. Автопортрет). Согласно народным воззрениям, в Духов день ушедшие предки посещают живых потомков. В этот день хорошим знаком был дождь с громом и грозой (На Троииу завтра красный денек будет. А на Духов День, попомни вот, замутится. А то и громком, может, погрозит. Всегда уж так. И. С. Шмелев. Лето Господне). Души предков приходили с того света к живущим на земле через врата, которые открываются только в Духов день. Духам в дар приносили жертву (Самая «разгульная» гроза состоялась в конце августа этого года. Это был 15-й день 7-го лунного месяца, так называемый «Духов день». Считается, что в этот день духи умериих через открывшиеся с того света ворота посещают наш мир. Их принято задабривать. И. Соколова. Бабочки летают).

Духов день праздновали на природе - в поле, в лесу. Жертва предкам была злаковой - это была каша, которую оставляли на земле. В этот день было принято гадать - спрашивать у кукушки «сколько лет осталось жить» (Помню <...> солнечное утро на Троииу, когда даже бородатые мужики, как истые потомки русичей, ульгбались из-под огромных березовых венков; помню грубые, но могучие песни на Духов день, когда мы с закатом уходили в ближнний дубовый лесок и там варили кашу, расставляли ее в черепках по холмикам и «молили кукуику" быть милостивой вещуньей... И. А. Бунин. Эпитафия). Гадание - женская практика. Природа в такой день давала знаки, указывающие на будущее.

С приходом новой религии в Духов день посещали церковь, где служили особую литургию в память об ушедших из этого мира (В Духов день призывает церковь за литургией «сотворить память всем от века умериим». Она возносит в этот день прекрасную и полную глубокого смысла молитву: - Вси рабы твоя, боже, упокой во дворах твоих и в недрах Авраама, - от Адама даже до днесь послужившая тебе чисто отизы наши, други и сродники! И. А. Бунин. Жизнь Арсеньева. Юность). В православии закрепилась традиция приносить цветы в церковь в Духов день и дарить их священникам (В храм всегда приходят с цветами. Не только в Троицу и Духов день, как у нас... И обязательно дарят цветы духовенству. Или вот ещзе обычай, который я нигде не встречал. А. Шаповалова. Экзарх Украины, Митрополит Киевский и Галицкий Иоанн // Журнал Московской Патриархии. 1945. № 3). Эта традиция о3начает принесение жертв земле: цветы - верный признак земной жертвы.

В Духов день совершались разные обряды. Среди них - целование земли. Забывание исходных причин ритуала связано со сменой религии. Память народа сохранила этот ритуал, а с чем он связан люди уже не помнят. Этот ритуал сейчас обыгрывается в разных спектаклях на подмостках театров (Первое действие - «Поцуелуй весны», на сиеене яркий весенний радостный день; происходит обряд целования земли старейшинами; надо заметить, что и по сей день во многих местностях России в Духов день землю считают именинницей. Танцы, хороводы, ритуаль - не малое поле для балетмейстера. Театральные новости // Вечернее время. 1912. 6 янв.).

Преемницей земли-матери в христианстве, как уже было сказано, стала Богородица - тоже мать. Ее называют также Богоматерь, Мать божья и т. д. В ее честь ходили с крестным ходом в поле в Духов день. Об этом пишет М. Горький (Но это не было решением. На другой день после праздника троицьь - в духов день - Самгин так же сидел у окна, выглядывая из-за цуветов на улииу. За окном тяжкко двигался крестный ход: обыватели города, во главе с духовенством всех цзерквей, или за город, в поле - провожать икону богородицы в далекий монастырь, где она пребывала и откуда ее приносили ежегодно в субботу на пасхальной неделе «гостить», по очереди, во всех ичерквах города... М. Горький. Жизнь Клима Самгина).

В мифологеме земля закреплен стереотип русской лингвокультуры, который «относится исключительно к содержательной стороне языка и культуры, т. е. понимается, прежде всего, как ментальный стереотип, и коррелирует с так называемой наивной картиной мира. Такой стереотип называют также языковым, имея в виду форму его проявления, сферу его репрезентации - в лексическом значении слова, в его коннотации, в семантической деривации, в синтаксисе, в сочетаемости, в идиоматике, в языковых тропах, в некоторых видах текстов, в частности, фольклорных» 
[26, с. 125]. Стереотип земли закрепляется в русской лингвокультуре в виде эпитетов именинница и матушка/мать. Языковой материал показывает, что сохранились отголоски сведений о божественной паре: «солнце - земля» и/или «небо - земля». Стереотип «схематизирует конкретный прототипический объект, но при этом выделяет, акцентирует в исходной когниции социально и этнокультурно значимое» [27, c. 14].

В XIX-XX вв. земля в русской лингвокультуре уже считалась вотчиной - землей отцов (Земля отцовская, прости, Страдалица родная... А. Т. Твардовский. Огонь). Отсюда слова Отчизна, Отечество. Род начинали от праотцов (Пославший в мир послал нас не за тем, Чтоб только сравнивать, как не похожи Земля изгнанья и былой Эдем, Ильлоно праотцев и это ложе. Е. Ю. Кузьмина-Караваева. Земли Твоей убогое житье...). В родовой земле покоились предки-отцы (Сыновья стояли на земле, но земля стояла на отцах, на их углях, тлеющих в золе, на их верных стареньких сердцах. Б. А. Слуцкий. Отцы и сыновья).

\section{Заключение}

Как показывает проведенный анализ языкового материала, в русской лингвокультуре сохранился образ древней богини земли. Известно ее имя - Макошь. Ей был посвящен праздник - Духов день, который знаменовал расцвет природы, сев, начало новой жизни - плодородие. Мифопоэтический образ земли наделяет ее признаками матери-родительницы-кормилицы-защитницы.

В русской лингвокультуре существует традиция отмечать именины земли на следующий день после Троицы - в Духов день. Обычно этот день выпадал на май. Майские грозы указывают на супруга земли - небо и персонифицированного бога Перуна. Стертые метафоры рождения указывают на тесную связь между землей, природой, родом, народом, урожаем, плодородием и материнством.

Культ земли-матери восходит к бытовавшему в эпоху матриархата культу Великой богини-матери. У многих народов этот культ также отмечен. В свою очередь, культ Земли-матери указывает на существование культа предков, сохранившегося до сих пор в японской культуре, называемого синтоизм. На существование этого культа указывают когнитивные признаки ритуальных действий (обрядовые песни, хоровод, целование земли, земные поклоны, жертвоприношение в виде злаковых и цветов - символов земли).

\section{ЛИТЕРАТУРА}

1. Мошина E. A. Гендерные и теоморфные признаки мифологемы Земля-мать в русской лингвокультуре // Вестник Кемер. гос. ун-та. 2020. Т. 22, № 1. С. 251-257.
2. Вишина М. Парадигма ключових понять міфологічного аналізу художнього тексту // Вісник Житомирського державного університету. 2010. Вип. 55. Філологічні науки. С. 140-143.

3. Барт P. Лингвистика текста // Текст : аспекты изучения семантики, прагматики и поэтики / Р. Барт и др. М., 2001. С. 168-175.

4. Lévi-Strauss C. The structural study of myth // Structural Anthropology. New York, 1963. Vol. I. Pp. 198-230.

5. Tylor E. B. Religion in Primitive Culture. New York : Harper \& Row, 1958. 552 p.

6. Фрэзер Дж. Дж. Золотая ветвь : исследование магии и религии. М. : АСТ, 1998. 781 с.

7. Eliade M. \& Trask Willard R. Myth and Reality. New York and Evanston : Harper \& Row, Publishers, 1968. 162 p.

8. Юнг К. Г. Архетип и символ. М. : Канон, 1991. $330 \mathrm{c}$.

9. Аникин В. П. Русский фольклор. М. : Высшая школа, 1987. $348 \mathrm{c}$.

10. Афанасьев А. Н. Поэтические воззрения славян на природу : опыт сравнительного изучения славянских преданий и верований в связи с мифическими сказаниями других родственных народов. М. : Современный писатель, 1865-1869. Т. 1-3.

11. Буслаев Ф. И. Этнографические вымыслы наших предков. М., 1868. 298 с.

12. Лосев А. Ф. Знак. Символ. Миф. Труды по языкознанию. М. : Экономика, 1994. 560 с.

13. Лотман Ю. М. Внутри мыслящих миров. Человек - текст - семиосфера - история. М. : Языки русской культуры, 1996. 447 с.

14. Мелетинский Е. М. Поэтика мифа. М. : Восточная литература, 1976. 406 с.

15. Мелетинский Е. М. Миф и историческая поэтика фольклора. М. : Наука, 1977. 389 с.

16. Потебня $A$. A. Символ и миф в народной культуре. М. : Лабиринт, 2007. 480 с.

17. Кобылко Н. А. Мифологема как ключевое понятие мифокритики : современные подходы // Современная филология : материалы III Междунар. науч. конф. (г. Уфа, июнь 2014 г.). Уфа : Лето, 2014. С. 4-6. URL: https://moluch.ru/conf/phil/archive/108/5817/

18. Мошина E. A. Реализация метафорической модели ЗЕМЛЯ-МАТЬ в русской языковой картине мира // Лингвистика XXI века : традиции и инновации : сб. науч. ст. к 30-летнему юбилею Санкт-Петербургского института иностранных языков / под общ. ред. М. В. Пименовой. СПб. : Изд-во СПбГЭУ, 2019. С. 135140. (Серия «Концептуальный и лингвальный миры». Вып. 23).

19. Мошина E. A. Мифологические параллели в метафорах земли в авторской картине мира М. И. Цветаевой // Языки и культура народов России и стран СНГ : сб. ст. / под общ. ред. М. В. Пименовой. СПб. : Изд-во СПбГУ, 2019. 159 с. С. 91-96. (Серия «Концептуальный и лингвальный миры». Вып. 17).

20. Пименова М. В. Этногерменевтика русской сказки : монография. М. : ИНФРА-М, 2018. 355 с. 
21. Ефремова T. Ф. Толковый словарь русского языка. URL: http://rus-yaz.niv.ru/doc/dictionary-efremova/fc/ slovar-200-7.htm\#zag-34959

22. Лауринкене Н. Мать Земля в литовской народной традиции // Балто-славянские исследования. XVIII : сб. науч. тр. М. : Наука, 2009. С. 486-503.

23. Еремеева С. А. Мифы славянского язычества. М., 1997. URL: http://www.vvvasilyev.ru/hist-isk/SAmenu.htm

24. Пименова М. В. Душа и дух : особенности концептуализации : монография. Кемерово : Графика, 2004. 386 с. (Серия «Концептуальные исследования». Вып. 3).

25. Левкиевская E. E. Демонология народная // Славянские древности : этнолингвистический словарь. М., 1999. T. 2. С. 51-56.

26. Топоров В. Н. К реконструкции балто-славянского мифологического образа Земли-Матери *Zemịā \& *Mātē (Māti) // Балто-славянские исследования, 19981999 : сб. науч. трудов. М., 2000. Т. 14. С. 239-371.

27. Толстая C. M. Стереотип в этнолингвистике // Речевые и ментальные стереотипы в синхронии и диахронии : тез. конф. М., 1995. С. 124-127.

\section{REFERENCES}

1. Moshina E. A. Gendernye i teomorfnye priznaki mifologemy Zemlja-mat'v russkoj lingvokul'ture [Gender and Theomorphic Signs of the "Earth-Mother" Mythologeme in Russian Linguistic Culture]. Vestnik Kemerovskogo gosudarstvennogo universiteta [Bulletin of Kemerovo State University]. 2020, Issue 22, No. 1. Pp. 251-257.

2. Vishina M. Paradigma kljuchovih ponjat'mifologichnogo analizu hudozhn'ogo tekstu [Paradigms of key concepts of mythological analysis of the text]. Visnik Zhitomirs'kogo derzhavnogo universitetu. 2010. Vip. 55. Filologichni nauki. Pp. 140-143.

3. Bart R. Lingvistika teksta [Text linguistics] Tekst: aspekty izuchenija semantiki, pragmatiki i pojetiki. R. Bart i dr. M., 2001. Pp. 168-175.

4. Lévi-Strauss C. The structural study of myth. Structural Anthropology. New York, 1963. Volume I. Pp. 198-230.

5. Tylor E. B. Religion in Primitive Culture. New York: Harper \& Row, 1958. 552 p.

6. Frjezer Dzh. Dzh. Zolotaja vetv': Issledovanie magii i religii [The Golden Bough: a Study in Magic and Religion]. M.: ACT, 1998. 781 p.

7. Eliade M. \& Trask Willard R. Myth and Reality. New York and Evanston: Harper \& Row, Publishers, 1968. 162 p.

8. Jung K. G. Arhetip i simvol [Archetype and symbol]. M.: Kanon, 1991. 330 p.

9. Anikin V. P. Russkij fol'klor [Russian folklore]. M.: Vysshaja shkola, 1987. 348 p.

10. Afanas'ev A. N. Pojeticheskie vozzrenija slavjan na prirodu: opyt sravnitel'nogo izuchenija slavjanskih predanij $i$ verovanij $v$ svjazi s mificheskimi skazanijami drugih rodstvennyh narodov [Poetry Views of Slavs on Nature: Experience of Comparative Study of Slavic Traditions and Beliefs in Connection with Mythical Tales of Other Related Peoples]. M.: Sovremennyj pisatel', 1865-1869. T. 1-3.
11. Buslaev F. I. Jetnograficheskie vymysly nashih predkov [Ethnographic fiction of our ancestors]. M., 1868. 298 p.

12. Losev A. F. Znak. Simvol. Mif. Trudy po jazykoznaniju [Sign. Symbol. Myth. Works on linguistics]. M.: Jekonomika, 1994. 560 p.

13. Lotman Ju. M. Vnutri mysljashhih mirov [In the conceiving worlds]. Chelovek - tekst - semiosfera - istorija. M.: Jazyki russkoj kul’tury, 1996. 447 p.

14. Meletinskij E. M. Pojetika mifa [Myth poetics]. M.: Vostochnaja literatura, 1976. $406 \mathrm{p}$.

15. Meletinskij E. M. Mif $i$ istoricheskaja pojetika fol'klora [Myth and historical poetics of folklore]. M.: Nauka, 1977. 389 p.

16. Potebnja A. A. Simvol $i$ mif v narodnoj kul'ture [Symbol and myth in folk culture]. M.: Labirint, 2007. $480 \mathrm{p}$.

17. Kobylko N. A. Mifologema kak kljuchevoe ponjatie mifokritiki: sovremennye podhody [Mythologeme as a key concept of critics of myths: modern approaches]. Sovremennaja filologija: materialy III Mezhdunar. nauch. konf. (g. Ufa, ijun' 2014 g.). Ufa: Leto, 2014. Pp. 4-6. Available at: https://moluch.ru/conf/phil/archive/108/5817/

18. Moshina E. A. Realizacija metaforicheskoj modeli ZEMLJa-MAT'v russkoj jazykovoj kartine mira [Implementation of the metaphorical model EARTH-MOTHER in the Russian language picture of the world]. Lingvistika XXI veka: tradicii i innovacii: sbornik nauchnyh statej $\mathrm{k}$ 30-letnemu jubileju Sankt-Peterburgskogo instituta inostrannyh jazykov. Pod obshhej red. M. V. Pimenovoj. SPb.: Izd-vo SPbGJeU, 2019. Pp. 135-140. (Serija «Konceptual'nyj i lingval'nyj miry». Vyp. 23).

19. Moshina E. A. Mifologicheskie paralleli v metaforah zemli v avtorskoj kartine mira M. I. Cvetaevoj [Mythological parallels in metaphors of the earth in the author's picture of the world M. I. Tsvetayeva]. Jazyki i kul'tura narodov Rossii i stran SNG: sbornik statej. Pod obshhej red. M.V. Pimenovoj. SPb.: Izd-vo SPbGU, 2019. Pp. 91-96. (Serija «Konceptual'nyj i lingval'nyj miry». Vyp. 17).

20. Pimenova M. V. Jetnogermenevtika russkoj skazki [Ethnohermeneutics of the Russian fairy tale]: monografija. M.: INFRA-M, 2018. 355 p.

21. Efremova T. F. Tolkovyj slovar' russkogo jazyka [Russian Language Dictionary]. Available at: http://rus-yaz. niv.ru/doc/dictionary-efremova/fc/slovar-200-7.htm\#zag34959

22. Laurinkene N. Mat' Zemlja v litovskoj narodnoj tradicii [Mother Earth in Lithuanian folk tradition]. Baltoslavjanskie issledovanija. XVIII: Sbornik nauchnyh trudov. M.: Nauka, 2009. Pp. 486-503.

23. Eremeeva S. A. Mify slavjanskogo jazychestva [Myths of Slavic paganism]. M., 1997. Available at: http:// www.vvvasilyev.ru/hist-isk/SAmenu.htm

24. Pimenova M. V. Dusha i duh: osobennosti konceptualizacii [Soul and Spirit: Features of Conceptualization]: monografija. Kemerovo: IPK «Grafika», 2004. 386 p. (Serija «Konceptual'nye issledovanija». Vyp. 3). 
25. Levkievskaja E. E. Demonologija narodnaja [Folk demonology]. Slavjanskie drevnosti: jetnolingvisticheskij slovar'. M., 1999. T. 2. Pp. 51-56.

26. Toporov V. N. K rekonstrukcii balto-slavjanskogo mifologicheskogo obraza Zemli-Materi *Zemịā \& *Mātē (Māti) [To reconstruction of a balto-Slavic mythological image of Zemli-Materi *Zemiā \& *Mātē (Māti)]. Balto-sla-

Военный институт (инженерно-технический) Военной академии материально-технического обеспечения имени генерала армии А. В. Хрулёва

Мочина Е. А., кандидат филологических наук, доиент кафедры иностранных языков

E-mail:moshina@inbox.ru

Поступила в редакциюю 21 марта 2020 г.

Принята к публикаичи 15 июня 2020 г.

\section{Для иитирования:}

Мошина E. A. О мифах и мифологемах лингвокультуры : Духов день - именины земли // Вестник Воронежского государственного университета. Серия: Лингвистика и межкультурная коммуникация. 2020. № 3. C. 130-139. DOI: https://doi.org/10.17308/lic.2020.3/2943 vjanskie issledovanija, 1998-1999: sb. nauch. tr. M., 2000. T. 14. Pp. 239-371.

27. Tolstaja S. M. Stereotip v jetnolingvistike [Stereotype in ethnolinguistics]. Rechevye i mental'nye stereotipy v sinhronii j diahronii: tezisy konferencii. M., 1995. Pp. 124-127.

Military Institute (Engineering and Technical) of the Military Academy of Material and Technical Support Army General A. V. Khrulev

Moshina E. A., Candidate of Philology, Associate Professor of the Foreign Languages Department

E-mail: moshina@inbox.ru

Received: 21 March 2020

Accepted: 15 June 2020

\section{For citation:}

Moshina E. A. Myths and mythologemes of the linguistic culture: Spirits Day - birthday of the earth. Proceedings of Voronezh State University. Series: Linguistics and Intercultural Communication. 2020. No. 3. Pp. 130-139. DOI: https://doi.org/10.17308/lic.2020.3/2943 